\title{
Vacuum Simulation of RF Cavities to Optimize Pump Configurations
}

\author{
S. Shen \\ L.S. Tung
}

This paper was prepared for submittal to the

Particle Accelerator Conference 1999

New York, NY

March 27-April 4, 1999

March 1999

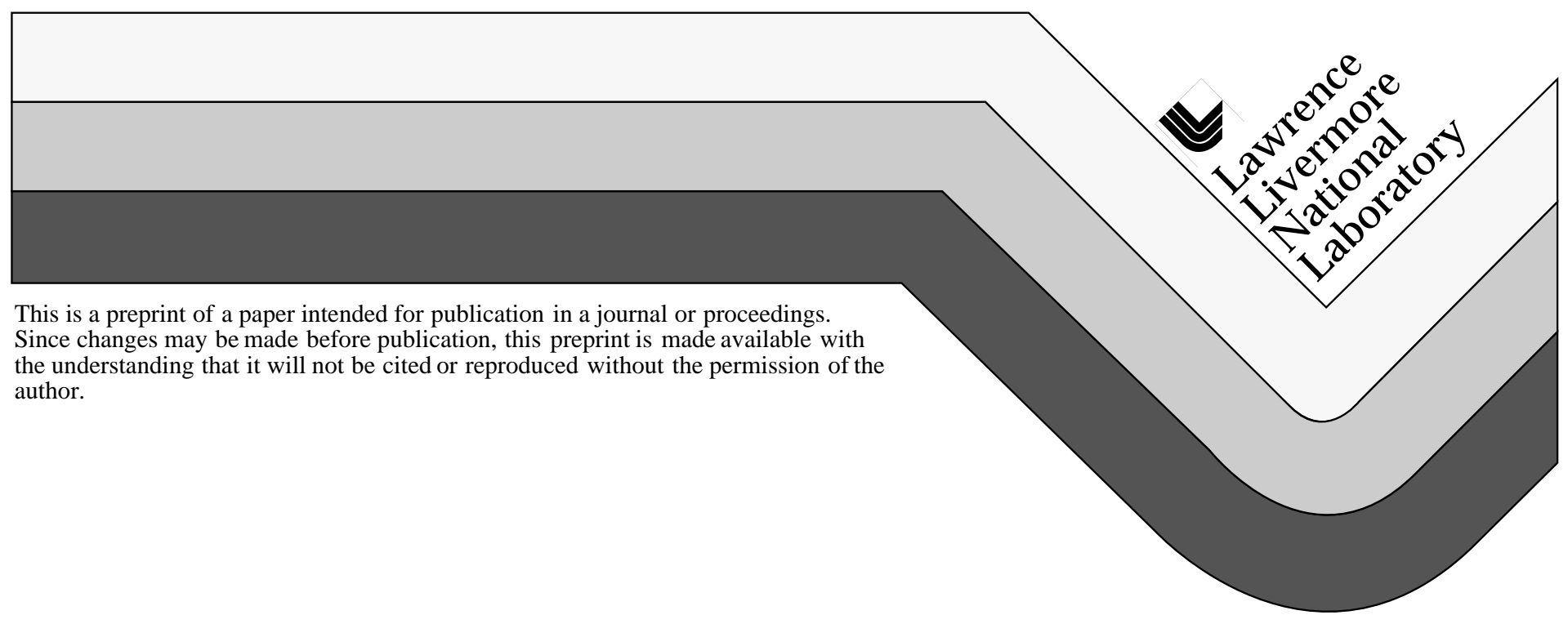




\section{DISCLAIMER}

This document was prepared as an account of work sponsored by an agency of the United States Government. Neither the United States Government nor the University of California nor any of their employees, makes any warranty, express or implied, or assumes any legal liability or responsibility for the accuracy, completeness, or usefulness of any information, apparatus, product, or process

disclosed, or represents that its use would not infringe privately owned rights. Reference herein to any specific commercial product, process, or service by trade name, trademark, manufacturer, or otherwise, does not necessarily constitute or imply its endorsement, recommendation, or favoring by the United States Government or the University of California. The views and opinions of authors expressed herein do not necessarily state or reflect those of the United States Government or the University of California, and shall not be used for advertising or product endorsement purposes. 


\title{
Vacuum Simulation of RF Cavities to Optimize Pump Configurations *
}

\author{
S. Shen, L. S. Tung ${ }^{\#}$, LLNL, Livermore, CA
}

\begin{abstract}
The pressure history in the components of an rf linac has been modeled using Mathematica.[1] Specifically the Cavity Coupled Drift Tube Linac (CCDTL) and Cavity Coupled Linac (CCL) sections of the Accelerator Production of Tritium (APT) plant [2] have been modeled in order to predict the optimal pump configuration over the 224 meter length. The pressure history in up to 43 sub-volumes within three representative modules (about three meters long) is analyzed in detail. Included in our model are timedependent outgassing rates and pressure-dependent pump speeds. With this information, we solve for the pressure history during roughing and with turbo and ion pumps. The number and size of each pump is optimized to achieve the desired pressure with minimal costs.
\end{abstract}

\section{APT DESCRIPTION}

A high-energy proton beam is accelerated by a series of rf cavities that have 11 different types of geometries or modules. The entire length of the 11 modules that encompass the CCDTL and CCL configurations is $224 \mathrm{~m}$. Over this length there are 341 (individually numbered) segments that are composed of from 1 to 7 rf cavity cells. Because the rf cavities and magnets surround the beam tube, the beam tube must be evacuated via pumping connected to the coupling cavities. Within each module, each cavity geometry is unique because of its dependence on the proton beam energy.

\section{VACUUM REQUIREMENTS}

The requirement for the CCDTL/CCL vacuum system is to provide sufficient pumping to overcome the surface outgassing of vacuum facing components and the rf window in order to maintain a beam tube pressure that is below $10^{-6}$ Torr. The system must be designed for plant operation, which implies continuous operation with minimal downtime. In addition if one ion pump fails per manifold, the remaining ion pump must keep the beam line below the operating pressure. The cavity components are composed of brazed OFE copper. The manifold, pumping ports, and beam tube are composed of electropolished 316 stainless steel.

\author{
"Work performed under the auspices of the U. S. Department of \\ Energy by the Lawrence Livermore National Laboratory under \\ contract number W-7405-ENG-48. \\ \# Email: 1stung@1lnl.gov \\ 2 VACUUM MODEL
}

\subsection{Overview}

The numerical model described here is for the vacuum system for a six-cavity section that represents the first module in the CCDTL. In actuality, the geometry of each cavity is unique because of its dependence on the proton beam energy. However in our model, the six cavities have the same size as the actual first cavity. This has the smallest geometry and so provides a conservative description without having to include the details for all the cavities.

We built two numerical models: first to study the effect of manifold size on the pumping configuration and second to take the first model with the optimized configuration and install an $\mathrm{rf}$ window system to determine its pumping needs. A layout of evacuated components for the first model is shown in Fig. 1. In the second model, the rf window and its pumping system are modeled as half a system and are placed after the $6^{\text {th }}$ cavity along a mirror symmetry line. In this way our 6-cavity model with the rf window system represents a 12 -cavity section with one manifold.

Figure 1 shows how the evacuated space is divided into sub-volumes and interconnecting conductances for the first model (without the rf window). Note that there are two ion pumps and one turbo pump shown for six cavities. However, as will be discussed shortly, the optimized configuration requires only two ion pumps and one turbo pump for 12 cavities. Consequently the pump speeds in the six-cavity model is exactly half of the actual pump speed. Two "half-speed" ion pumps are used so that we can shutoff one pump to study the pressure gradient along the beam tube. (A 12-cavity model will be written in the near future with only "whole pumps".)

\subsection{Method}

Pressure history is studied by solving the coupled the energy balance between all the sub-volumes. (The routine is written with Mathematica [1] and runs on a $266 \mathrm{MHz}$ Power Mac G3. The entire run requires at most 70 sec.) For each sub-volume, the following energy balance equation is solved simultaneously for all 43 volumes for each time during pumpdown. 


$$
V_{i} d p_{i} / d t=\Sigma Q_{i-i n}-\Sigma Q_{i-o u t}
$$

$V$ is the volume (liters);

$d p / d t$ is the rate of change in pressure (Torr/sec);

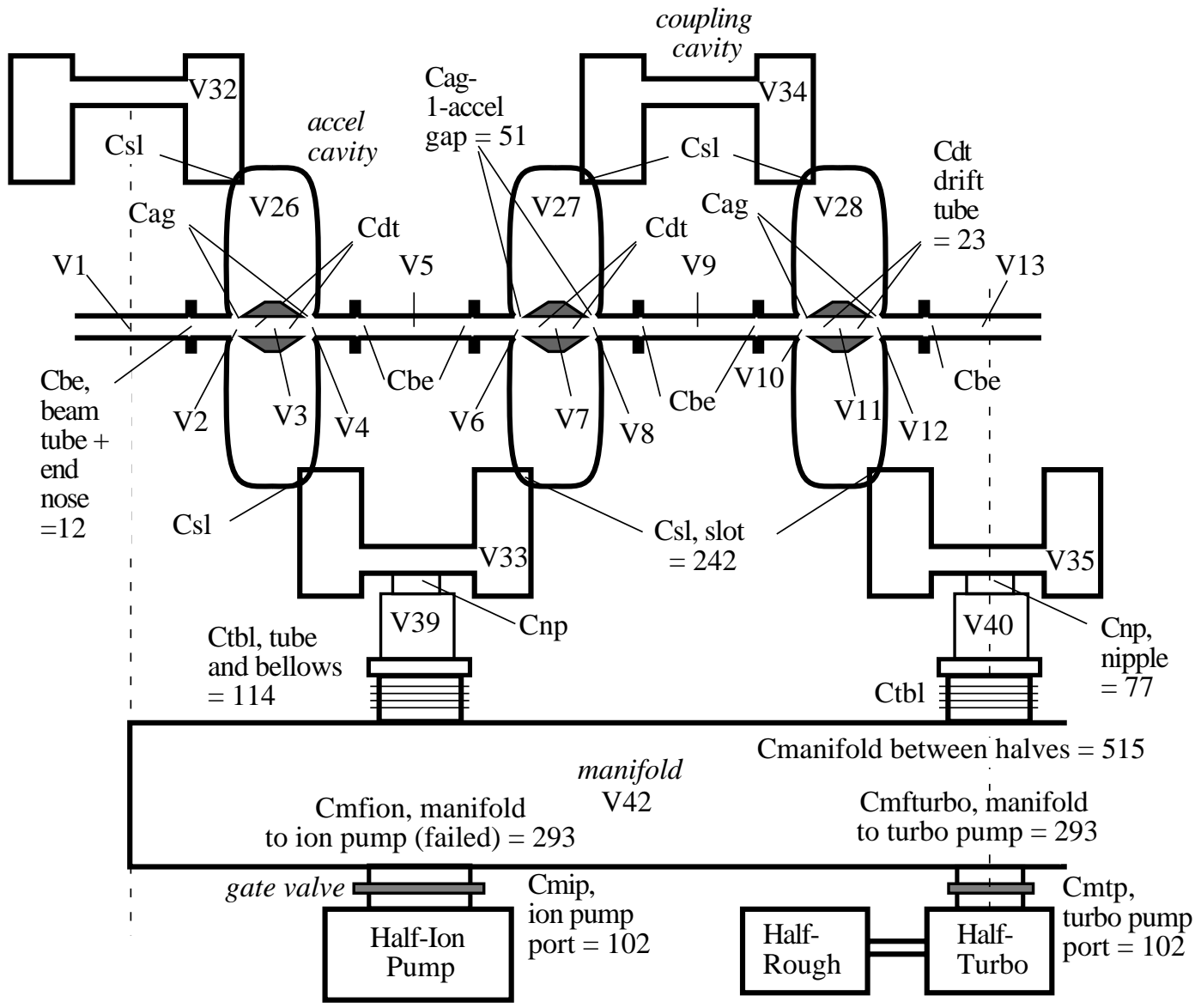

where $i$ is the index for the $i t h$ sub-volume,

Figure 1: Evacuated space for the first six cavities of the APT/CCDTL as divided into sub-volumes and conductances. Only the left half of the layout is shown. The right half is symmetric to the left. Sub-volumes are labeled numerically and indicated with a "V". Conductances are labeled with the actual conductance values in lit/sec. Note that between each sub-volume is a conductance.

$\Sigma Q_{i-i n}$ is the sum of time-dependent outgassing or leaking into $V_{i}$ (Torr-lit/sec); and $\Sigma Q_{i-\text { out }}$ is sum of energy removed from $V_{i}$ via conduction, $Q_{i \text {-out }}=C_{i \rightarrow j}\left(p_{i}-p_{j}\right)$

and $C_{i \rightarrow j}$ is the conductance (lit/sec)

between sub-volumes;

and/or via pumping, $Q_{\text {i-out }}=S\left(p_{i}\right) p_{i}$

and $S\left(p_{i}\right)$ is the pressure-dependent

pumping speed (lit/sec).

This set of equations is solved four times: 1) with the roughing pump down to 0.05 Torr; 2) with the turbo pump down to $4 \times 10^{-7}$ Torr; 3) with the ion pumps down to below $2 \times 10^{-7}$ Torr; and 4) with one ion pump off for 50 seconds. The roughing pump pressure is initially at 720 Torr. The final pressure at the end of each pumping phase is then saved to be the initial pressure for the next pumping phase.

\section{DETAILED RESULTS}

\subsection{Final characteristics}

Aside from geometry, surface outgassing is the strongest factor to determine pumping needs. For our time-dependent model, we combined the early outgassing rates of stainless steel from Roth [3] with long term rates after ten hours. The long term rates are dependent on the final material preparation and handling. We derived a numerical fit that describes this time-dependence of outgassing:

$R\left[\right.$ Torr-lit $\left./ \mathrm{sec} / \mathrm{cm}^{2}\right]=2.4 \times 10^{-8} \exp (-2.2 \times$

$\left.10^{-3} t\right)+7.2 \times 10^{-8} \exp \left(-1.7 \times 10^{-3} t\right)+B$,

where $B=1 \times 10^{-10}$, the outgassing rate after ten hours and $t$ is time in seconds. 
For a ten-fold in increase in $R$, we found that the base pressure followed linearly.

A summary of the total area, volumes, and outgassing is provided in Table 1. Also given is the final optimized pumping configuration. Following this table, Fig. 2 shows the pumping history. When one ion pump fails, our model shows that the beam tube pressure above the failed pump nearly doubles within 50 seconds.

Table 1: Summary of geometry, optimized pumping configuration, and final pressures

\begin{tabular}{|l|}
\hline Pumping System for 12 Cavities \\
\hline One 6" diameter manifold \\
\hline One 300 lit/min roughing pump \\
\hline One 70 lit/sec turbo pump \\
\hline Two 55 lit/sec ion pumps (for redundancy) \\
\hline $\begin{array}{l}\text { Three gate valves (one for each turbo and ion } \\
\text { pump) }\end{array}$ \\
\hline $\begin{array}{l}\text { Detailed system parameters for a 12-cavity } \\
\text { section (including manifold and pumping } \\
\text { ports but no rf window) }\end{array}$ \\
\hline Total copper surface area $=42,582 \mathrm{~cm}^{2}$ \\
\hline Total stainless steel surface area $=16,920 \mathrm{~cm}^{2}$ \\
\hline Total volume $=137$ lit \\
\hline Total surface outgassing $=5.9 \mathrm{x} 10^{-6}$ Torr-lit $/ \mathrm{sec}^{2}$ \\
\hline $\begin{array}{l}\text { Beam tube pressure during normal ion pump } \\
\text { operation }=1.4 \mathrm{x} 10^{-7} \text { Torr }\end{array}$ \\
\hline $\begin{array}{l}\text { Beam tube pressure with one ion pump failed } \\
=2.5 \mathrm{x} 10^{-7} \text { Torr }\end{array}$ \\
\hline
\end{tabular}

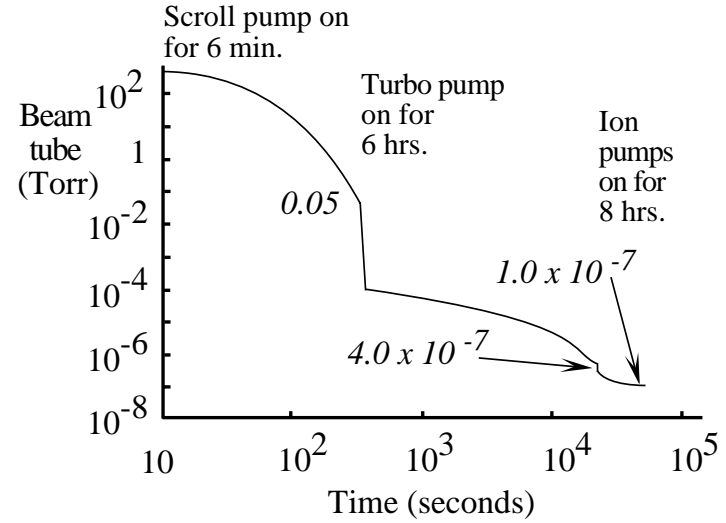

Figure 2: Pressure history of optimized pumping of 12 cavities for the first module of the APT/CCDTL

\subsection{Component Optimization}

The vacuum components that we optimized were manifold diameter and length, bellows size (between the lower coupling cavities and manifold), and pump number and size.
The largest contribution to optimization was the manifold. Use of a manifold allows the use of fewer larger pumps. For the same total pumping speed, one can look at prices in the vender catalogs and conclude that for the same total pumping speed, fewer larger pumps cost substantially less than more smaller pumps. In our case of ion pump failure, if the manifold diameter is too small, the reduction in manifold conductance reduces pumping of the beam tube above the failed pump. If the manifold diameter is too large, the additional outgassing increases the beam tube pressure. Thus our simulation determined that a 6" or 8" diameter allows the most cost effective pumping configuration. In addition, because the manifold is attached from above and the accelerator is supported on box beams that are spaced 18" apart, then a 6" or smaller manifold is much easier to install. Thus we chose a 6" diameter manifold.

Pump sizes were chosen so that the smallest pump size available from vendors evacuated the beam tube to below $2 \times 10^{-7}$ Torr. Thus with the failure of one ion pump the beam tube pressure would be less than $4 \mathrm{x}$ $10^{-7}$ Torr. In this way we have a considerable design margin in case the surface outgassing exceeds $10^{-10}$ Torr-lit $/ \mathrm{sec} / \mathrm{cm}^{2}$.

A second study included an rf window assembly (with its own pump) at the location of sub-volume 38. Based on preliminary outgassing data for the rf window, the assumed rate was $2.7 \times 10^{-5}$ Torr-lit/sec.[4] We ran the code for a range of window pumping speeds and looked at beam tube and rf window pressures. Maintaining a pressure of at least $1 \times 10^{-7}$ Torr in the $\mathrm{rf}$ window volume was an operational requirement. To accomplish this required that the rf window pumping speed be at least $275 \mathrm{lit} / \mathrm{sec}$. Because of the small space and weight restrictions, a NEG (non-evaporable getter) pump was chosen for this job. With no window pumping, the rf window pressure reached $7 \times 10^{-5}$ Torr. Based on available NEG pump designs, we conservatively chose a pump size of $500 \mathrm{lit} / \mathrm{sec}$.

\section{EXTRAPOLATION TO PLANT}

We also analyzed two other representative modules one in the CCDTL section and the third in the CCL section. The optimized configuration for each section modeled is then linearly extrapolated to the entire 341 segments to characterize the pumping needs for the plant.

\section{REFERENCES}

[1]Mathematica version 3.0 by Wolfram.

[2]R. L. Wood et al., "Status of Engineering Development of CCDTL for Accelerator Production of Tritium," Proc. LINAC98, Chicago.

[3]Roth, A., 1996, Vacuum Technology, (North Holland, Amsterdam) 190.

[4]APT/LEDA RFQ RF Window Pumping System, Sept. 24, 1997. 